\title{
Expanding the Boundary of Water Tolerant Frustrated Lewis Pair Hydrogenation: Enhanced Back Strain in the Lewis Acid Enables the Reductive Amination of Carbonyls
}

\author{
Éva Dorkó[ ${ }^{[a]}$, Márk Szabó ${ }^{[b]}$, Bianka Kótai ${ }^{[a]}$, Imre Pápai ${ }^{[a]}$, Attila Domján ${ }^{[b]}$ and Tibor Soós ${ }^{*[a]}$
}

\begin{abstract}
We report here the development of a boron/nitrogen centered frustrated Lewis pair (FLP) with remarkable high water tolerant property. As systematic steric tuning of the boron-based Lewis acid (LA) component revealed, the enhanced back-strain engenders water binding increasingly reversible in the presence of relatively strong base. This advance allows to expand the limit of FLP's hydrogenation as demonstrated by the FLP reductive amination of carbonyls. This metal-free catalytic variant displays a notable broad chemoselectivity and generality.
\end{abstract}

Frustrated Lewis pairs (FLP) chemistry is a discrete activation mode that can be utilized for metal-free catalysis. ${ }^{[1]}$ One of these applications, the FLP hydrogenation ${ }^{[2,3]}$, has sparked scientific upheaval with a promise to develop metal-free hydrogenation technology. Since the inception of this new paradigm, the scope and utility of the FLP hydrogenation have been continually expanded and several key limitations have been solved. This is aptly exemplified by the FLP reduction of carbonyl compounds and the water tolerant hydrogenation of various ketones and aldehydes. ${ }^{[4]}$ Despite the progress in FLP hydrogenation, water tolerance is still limited to boron/oxygen centered FLPs, and the currently used boron-based Lewis acids (LA) are,incompatible with water if more basic Lewis bases (LB), such as amines or phosphines are incorporated into the FLP hydrogenation catalyst. ${ }^{[5]}$ This restrain is not merely a technical concern, but it represents a major obstacle to expand the utility of FLP hydrogenation toward hydrogenation-condensation tandem reactions. ${ }^{[4,6]}$ Herein, we show that it is possible to tackle this constrain via developing a structurally well-designed boronbased LA for FLP chemistry. The resulting FLP not only fulfilled the premise of water tolerant boron/nitrogen centered FLP hydrogenation catalyst, but also enabled us to develop metal-free FLP reductive amination of carbonyls ${ }^{[7]}$ with hydrogen.

From the appearance of the FLP hydrogenation, the catalytic procedures were overwhelmingly accomplished with $\mathrm{B}_{(}\left(\mathrm{C}_{6} \mathrm{~F}_{5}\right)_{3}$ as a sterically overcrowed LA combined with nitrogen, phosphorous or oxygen centered LBs. The high oxophilicity of the boron center, however, renders these hydrogenation catalysts extremely

[a] É. Dorkó, B. Kótai, Prof. Dr. I. Pápai, Dr. T. Soós Institute of Organic Chemistry, Hungarian Academy of Sciences, Research Centre for Natural Sciences

Magyar tudósok körútja 2, 1117 Budapest (Hungary)

E-mail: soos.tibor@ttk.mta.hu

[b] M. Szabó, Dr. A. Domján

NMR Research Laboratory of IC, Hungarian Academy of Sciences,

Research Centre for Natural Sciences

Magyar tudósok körútja 2, 1117 Budapest (Hungary)

Supporting information for this can be found under: sensitive toward moisture. The catalyst deactivation by water, however, is more than an interaction of water and the LA, it is actually an FLP reaction (Figure 1). Thus, the strength of the water binding to boron center can be significantly enhanced by deprotonation of the added LBs, (the Brønsted acidity of $\mathrm{H}_{2} \mathrm{O}$ $\mathrm{B}\left(\mathrm{C}_{6} \mathrm{~F}_{5}\right)_{3}{ }^{[8]}$ is comparable to $\mathrm{HCl}\left(\mathrm{p} K_{\mathrm{a}}=8.4(\mathrm{MeCN})\right)$.

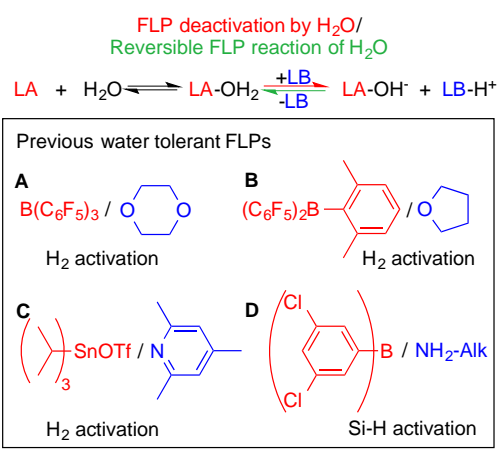

Figure 1. The irreversible/reversible FLP reaction of water and catalyst developments to overcome water inhibition

This leveraging effect of LBs is well illustrated by the observation that the archetypal $L A, B\left(C_{6} F_{5}\right)_{3}$ can only form a water tolerant FLP hydrogenation catalyst as long as a rather weakly basic solvent, such as $1,4-$ dioxane is applied as an LB. ${ }^{[4]}$ Thus, in the presence of a stronger LB, even such as THF, the $\mathrm{B}\left(\mathrm{C}_{6} \mathrm{~F}_{5}\right)_{3}$ LA is irreversible inhibited. To minimize the limiting interference of water in the presence of more basic oxygencentered LB, the deliberate combination of steric and electronic tuning for the Lewis acidic component are required. The employed enhanced steric shielding around the LA center serves to prevent or retard the complexation ability with LBs (including water), ${ }^{[9]}$ while retaining the capacity of cleavage of the small hydrogen molecule with oxygen-centered LBs. ${ }^{[4 \mathrm{~d}, \mathrm{f}]}$

There have been also efforts to push the water-tolerance limit of nitrogen-centered FLPs through the development of LAs. One of the possible solutions is the change of the boron center in FLPs into a heavier element to result in a still strong but softer Lewis acid, as has been demonstrated by Ashley and coworkers. ${ }^{[5]}$. Other noteworthy advance in the boron series is the recent development of a non-fluorinated boron $L A B(3,5$ $\left.\mathrm{Cl}_{2} \mathrm{C}_{6} \mathrm{H}_{3}\right)_{3}$ for FLP promoted reductive amination of carbonyls with silanes. As Fasano and Ingleson has recently recognized, ${ }^{\left[{ }^{6 d]}\right]}$ the electronic tuning alone afforded a weaker LA that can tolerate water even in presence of alkyl amines. Albeit an important step forward, the applicability of this boron/nitrogen centered FLP catalyst appears to be limited, the cumulative LA/LB strength was efficient for silane activation, but not for $\mathrm{H}_{2}$ heterolysis. Consequently, the issue of water tolerant bo- 
ron/nitrogen centered FLP hydrogenation, which can be used in hydrogenation-condensation tandem reactions, has remained unresolved.

Based on the above, it seems that the electronic tuning in borane series reached its limit and we anticipated that the steric effects could be considered as a major factor to improve further the water tolerance of boron-centered Lewis acids. However, the efficiency of any structural modifications is hampered by the gaps of understanding how the varying front- and back-strain ${ }^{[10]}$ affect the LAs strength and reactivity. We thus attempted to achieve an insight via screening a series of boranes with gradually different local steric environments around the boron atom. We selected tris(2-chloro-6-fluoroaryl)borane I, as a starting point for this study and devised to enhance its front- and backstrain by the stepwise exchange of fluorine to chlorine atoms. For the synthesis of these asymmetrically substituted boranes (I, II and III, see Scheme 1.) a scalable procedure was developed based on previously described method. ${ }^{[4 d]}$

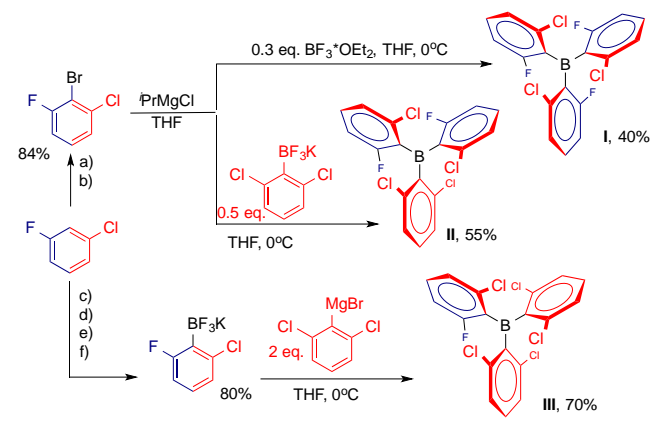

Scheme 1. Synthesis of halogenated boranes. Conditons: a) 1.1 eq. BuLi in THF; b) 1,5 eq. $\mathrm{Br}_{2}$; c) 1.1 eq. BuLi in THF, $-78^{\circ} \mathrm{C}$; d) 2 eq. $\mathrm{B}(\mathrm{OMe})_{3}$; e) 1.4 eq. $1 \mathrm{M} \mathrm{HCl}, 0^{\circ} \mathrm{C}$; f) 4 eq. $\mathrm{KHF}_{2}$ in $\mathrm{MeOH} / \mathrm{H}_{2} \mathrm{O}$.

As LA strength is situation dependent and likely not possible to determine on an absolute sense, we used multiple methods to gain detailed knowledge about the synthesized boranes. First, we performed a cyclic voltammetry (CV) study of I-III to gauge the electronic consequences of the successive replacement of fluorine atom with chlorine (Table 1, entry 1). These reduction potentials can be considered as the approximate electrophilicity of the boron centers in absence of the steric effect, as previous electrochemical studies on sterically congested boranes suggested. ${ }^{[11]}$ From this study, an additive relationship was observable, the reduction potential of boranes was found to shift to less negative potentials and the voltammetry became more reversible as the number of chlorine substituents increased around the boron center. This tendency is consistent with the greater electron-withdrawing capacity and steric demand of chlorine.

Next, Gutmann-Beckett method ${ }^{[12]}$ was used to assess the relative Lewis acidity of I-III boranes (entry 2). This empirical method gave a reverse order within the series, so the most fluorinated borane I formed the strongest dative adduct. Thus, the increasing sterical strain (both front- and back-strain) engendered by the fluorine-chlorine exchange counters the gains made by the increasing electron-withdrawing power of more chlorine substituents.

Table 1. Evaluation of relative Lewis acidity of boranes I-III.

\begin{tabular}{ccccc}
\hline Entry & Method & I & II & III \\
\hline 1 & Cyclic Voltammetry $^{[\mathrm{a}]}$ & $-2.1 \mathrm{~V}$ & $-2.0 \mathrm{~V}$ & $-1.9 \mathrm{~V}$ \\
2 & Gutmann-Beckett $^{[\mathrm{b}]}$ & $77 \%$ & $5 \%$ & $4 \%$ \\
3 & Relative hydricity $^{[\mathrm{cc}]}$ & $\begin{array}{c}-15.3 \\
\mathrm{kcal} / \mathrm{mol}\end{array}$ & $\begin{array}{c}-16.0 \\
\mathrm{kcal} / \mathrm{mol}\end{array}$ & $\begin{array}{c}-17.2 \\
\mathrm{kcal} / \mathrm{mol}\end{array}$ \\
\hline
\end{tabular}

[a] Reduction potentials (in V) measured by $\mathrm{CV}$, for borane $\mathrm{I}$ only the $\mathrm{E}_{\underline{0 x}}$ can be determined. [b] Relative $\%$, the $0 \%$ and $100 \%$ reference points are the ${ }^{31} \mathrm{P}$ NMR chemical shift of $\mathrm{Et}_{3} \mathrm{P}=\mathrm{O}$ and its adduct with $\mathrm{B}\left(\mathrm{C}_{6} \mathrm{~F}_{5}\right)_{3}$. [c] Gibbs free energy of isodesmic reaction $\mathrm{LAH}^{-}+\mathrm{B}\left(\mathrm{C}_{6} \mathrm{~F}_{5}\right)_{3} \rightarrow \mathrm{LA}+\mathrm{B}\left(\mathrm{C}_{6} \mathrm{~F}_{5}\right)_{3} \mathrm{H}^{-}$. Lower energy value refers to weaker Lewis acidity as compared to $B\left(C_{6} F_{5}\right)_{3}$.

Perhaps more surprising is the finding that the trend within the series is not linear and even one chlorine-fluorine replacement exerts such a cumulative steric penalty in Lewis acid II that it practically impedes the dative adduct formation with $\mathrm{Et}_{3} \mathrm{P}=\mathrm{O}$ probe. In an effort to distinguish between the two steric factors, we computed the relative thermodynamic hydricity ${ }^{[13]}$ of boranes I-III via DFT calculations taking the archetypal $\mathrm{LA} \mathrm{B}\left(\mathrm{C}_{6} \mathrm{~F}_{5}\right)_{3}$ as a reference compound (entry 3). ${ }^{[14]}$ As hydride anion $\left(\mathrm{H}^{-}\right)$is the smallest possible LB, the steric penalty to reach the boron center (front-strain) is minimal. Therefore, the strength of hydride binding is determined by the electronic effect and the steric penalty emerging upon the pyramidalization of the boron, the back-strain. The computational data indicate that the relative hydricity decreases only slightly within the series and no such a drastic drop can be observed as in the acidity scale measured by the Gutmann-Beckett method. Consequently, the difference in acidity trends is due to front-strain that serves to traverse the complexation of a larger LB. An additional way to interpret the above data (entry 1 and entry 3 ) is to view these bulky boranes as a structurally "spring-loaded" system with "increasing force constant" upon hydride binding. Whereas each $\mathrm{F}-\mathrm{Cl}$ replacement increases the electrophilicity of the borane, the increment of electrophilicity is counterweighted as the gradually growing back-strain increasingly strives to push back the boron center into the original $\mathrm{sp}^{2}$ state

A final evaluation of these boranes was the study of their water complexation ability in the presence of a relatively strong aliphatic amine base. In these NMR studies DABCO was used as a non-coordinating base and conclusions rest upon ${ }^{1} \mathrm{H},{ }^{10} \mathrm{~B}$, ${ }^{19} \mathrm{~F}$, DOSY, NOESY and EXSY NMR results. First, detailed structural information were obtained by means of ${ }^{1} \mathrm{H}$ single-pulse, DOSY and NOESY experiments about $\mathrm{BAr}_{3}-\mathrm{H}_{2} \mathrm{O}-\mathrm{DABCO}$ complexes (See the Supporting Information). The NMR studies indicate that DABCO and water form a 1:1:1 complex with all I-III boranes. Furthermore, DABCO is in fast exchange between the two protons of water at room temperature, so one signal can be observed for the water. However, lowering the temperature of the NMR sample to $-30^{\circ} \mathrm{C}$ causes de-coalescence of water protons into a pair of sharp signals. 


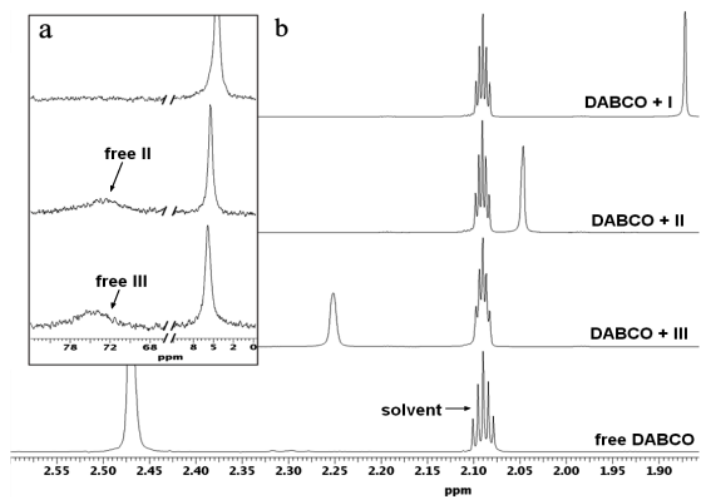

Figure 2. a) ${ }^{10} \mathrm{~B}$ NMR of the boranes I-III in DABCO/ $\mathrm{H}_{2} \mathrm{O} /$ borane I-III complexes at $45^{\circ} \mathrm{C}$ (signals at $5.0 \mathrm{ppm}$ are dative complexes). b) ${ }^{1} \mathrm{H}$ NMR signal of $\mathrm{DABCO}$ in the same ternary aqua complexes at $45^{\circ} \mathrm{C}$ and the free DABCO (signal at $2.09 \mathrm{ppm}$ is due to solvent).

Further and more significant structural dynamics of ternary aqua complexes is revealed from ${ }^{1} \mathrm{H}$ and ${ }^{10} \mathrm{~B}$ NMR studies at $45^{\circ} \mathrm{C}$ (Figure 2). Whereas DABCO/ $\mathrm{H}_{2} \mathrm{O} /$ borane I adduct remains intact at this temperature, the other two ternary aqua complexes considerably dissociate to free borane II and III (45\% and $60 \%$ respectively). Accordingly, these borane II or III/DABCO pairs can be used for FLP activations in presence of equimolar water, as free borane and DABCO are available for hydrogen cleavage. To gain further insight, 2D EXSY NMR spectroscopy ${ }^{[15]}$ was used to explore quantitatively the dynamic behaviour of water dissociation. This method enabled us to determine rate constants and activation parameters of the dissociation of the ternary aqua complexes of boranes II and III (see Supporting Information). Whereas the stability of the $\mathrm{DABCO} / \mathrm{H}_{2} \mathrm{O} /$ borane II and III complexes is similar, there is a significant difference in kinetics as the exchange rate is nearly 20 times higher for the aqua complex of borane III ( $11.0 \mathrm{vs} .0 .57 \mathrm{~s}^{-1}$ at $\left.35^{\circ} \mathrm{C}\right)$. This can be correlated with the increased steric profile of III, especially, the enhanced back-strain may play a key role. The results of the above studies corroborate that Lewis acidity is a situation dependent phenomenon and underscore the importance of steric tunings to reach certain designer goals.

After identifying borane/amine FLPs with water tolerance, we conducted some preliminary experiments to ascertain their utility in FLP hydrogenations. First, the metal-free reduction of tert-butylbenzaldimine (1) to tert-butylbenzylamine (2) was probed under inert conditions. Gratifyingly, all I-III boranes were found to be amenable to promote the reduction at $80^{\circ} \mathrm{C}$ with DABCO base (Table 2, entry 1), however, there was a difference at room temperature reductions (entry 2). This result is consistent with the sterical accessibility and hydricity of the applied LAs.

Next, our major objective, the prospect of water tolerant FLP hydrogenation was probed in reductive amination reaction. The reaction of benzaldehyde (3) with benzylamine (4) was selected as a test reaction using $10 \mathrm{~mol} \%$ borane catalysts in the presence of molecular sieves. To our delight, the desired catalytic reduction could be performed selectively, no competing reduction to benzylalcohol occurred and water was compatible with boranes at $80^{\circ} \mathrm{C}$. As expected, the presence of water had a significant impact on the FLP catalysts' performance, the reactions slowed down and a reverse order in efficiency was observed (entry 3). Notably, the application of catalyst III allowed to run the reaction at lower temperature $\left(55^{\circ} \mathrm{C}\right.$, entry 4$)$ and, most importantly, without water-scavenger (entry 5). Thus, borane catalyst III is a superior catalyst to I and II, it can tolerate even 10 equivalents of water in FLP promoted reductive amination. Finally, it is important to note that the presence of water might be advantageous as the borane-water adduct can function as a Bronsted acid catalyst in an auto-tandem catalytic process. ${ }^{[4]}$

Table 2. Conversions of FLP reduction of imine 1 and FLP reductive amination

\begin{tabular}{|c|c|c|c|c|c|}
\hline Entry & $T\left[{ }^{\circ} \mathrm{C}\right]$ & $t[\mathrm{~h}]$ & I. & II. & III. \\
\hline $1^{[\mathrm{a}]}$ & $80^{\circ} \mathrm{C}$ & $24 \mathrm{~h}$ & $99 \%$ & $99 \%$ & $99 \%$ \\
\hline $2^{[a]}$ & r.t. & $24 \mathrm{~h}$ & $62 \%$ & $21 \%$ & $0 \%$ \\
\hline $3^{[\mathrm{b}]}$ & $80^{\circ} \mathrm{C}$ & $72 \mathrm{~h}$ & $78 \%$ & $99 \%$ & $99 \%$ \\
\hline $4^{[b]}$ & $55^{\circ} \mathrm{C}$ & $72 \mathrm{~h}$ & $0 \%$ & $0 \%$ & $14 \%$ \\
\hline $5^{[\mathrm{b}][c]}$ & $80^{\circ} \mathrm{C}$ & $72 \mathrm{~h}$ & - & $44 \%$ & $99 \%$ \\
\hline
\end{tabular}

[a] Reaction condition: $0.25 \mathrm{mmol}{ }^{t} \mathrm{Bu}$-benzaldimine (1), 4 bar $\mathrm{H}_{2}, 10 \mathrm{~mol} \%$ borane, $10 \mathrm{~mol} \%$ DABCO, toluene, $24 \mathrm{~h}$. [b] Reaction condition: $0.25 \mathrm{mmol}$ benzaldehyde (3) and $0.25 \mathrm{mmol}$ benzylamine, 20 bar $\mathrm{H}_{2}, 10 \mathrm{~mol} \%$ borane toluene, $100 \mathrm{mg}$ molecular sieves. [c] Reactions run without molecular sieves.

Having identified borane III as a competent, as well as water tolerant LA for FLP reductive amination, we next focused on exploring its scope and limitation. We were pleased to find that a wide array of amines and carbonyls can undergo FLP promoted reductive amination with high selectivity, no side reactions, especially no carbonyl reduction to alcohol, could be detected. This can be correlated with the renewable borohydride character of the catalyst. As shown in Scheme 2, both aliphatic and aromatic amines can be used as LB in the reductive coupling $(6,7)$ the developed FLP is highly tolerant of a wide range of functional groups, thus ether $(\mathbf{8}, \mathbf{9})$ and ester $(\mathbf{1 0})$, as well as heteroaromatic rings (11-13) do not irreversible inhibit the catalysis. Moreover, the method displays high chemoselectivity, it tolerates several functionalities that are prone to reduction, including chlorine $(14,15)$, bromine (16), cyclopropyl $(18)$, olefin $(19,21$, 22) and acetylene (20). The reduction of imines of sterically hindered amines such as tert-butylamine and diisopropyl-amine are slower; therefore these products $(\mathbf{2 4}, \mathbf{2 8})$ can be isolated with only moderate yields. As a further proof for versatility, we found that chiral secondary amines can be used in this protocol, as only negligible racemization was observed in 1-phenylethy products $\mathbf{2 9}$ and $\mathbf{3 0}$. It was expected and then observed that the steric demand of the reducing agent affects the outcomes of the reductions. Thus, cinnamaldehyde can be chemoselectively reduced to allylamine derivative $\mathbf{2 2}$ without the saturation of the olefinic group. Furthermore, 4- ${ }^{t} \mathrm{Bu}$-cyclohexanone was transformed selectively to the corresponding cis-amino derivative $\mathbf{3 2}$, 
so the transiently formed bulky borohydride attacks the corresponding imine equatorially. We also assumed that the steric contribution of the reducing agent could be used to secure diastereoselectivity in chirality transfer reactions. Thus, the reductive amination of methyl-ethylketone with enantiopure 1phenylethylamines was probed. Despite the moderate diastereomeric ratio, $2: 1$, it is a promising result for substrates having such a small steric difference $(33,34)$. Finally, the double methylation of primary amine was accomplished using formaldehyde (35). Notably, the water tolerance of the developed FLP allowed using $37 \%$ aqueous solution of formaldehyde. Thus, even aqueous two-phase (water-toluene) reaction can be performed with high conversion.
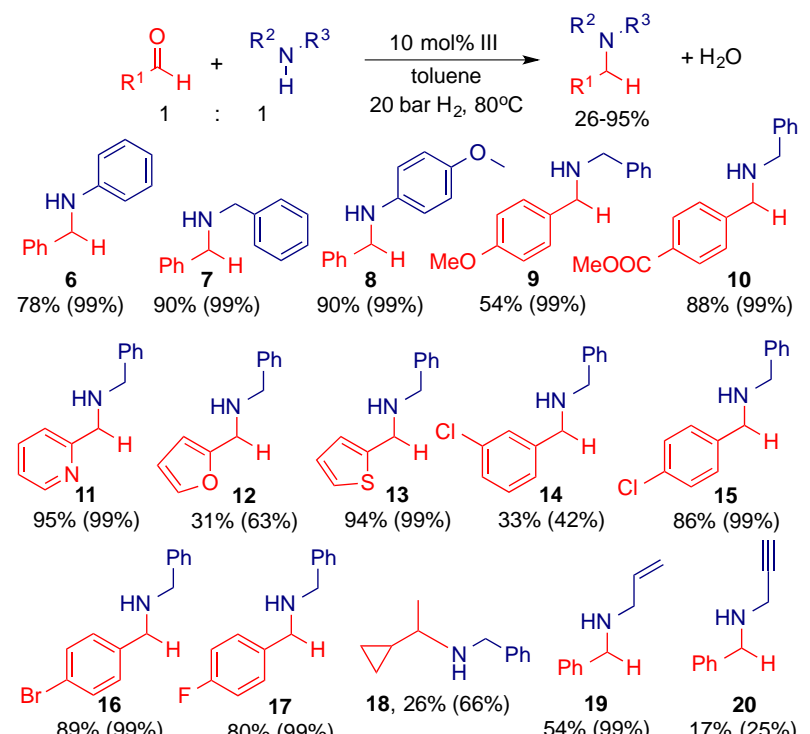

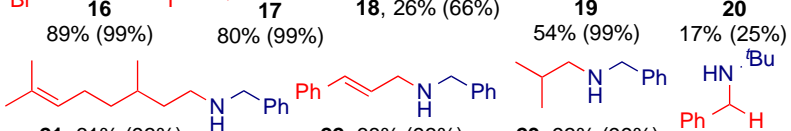

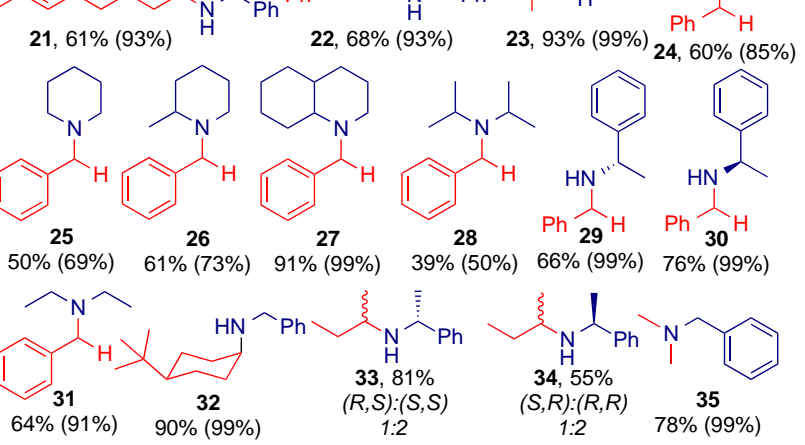

Scheme 2. FLP reductive amination of carbonyl compounds using borane III as a catalyst. The applied reaction condition: $80^{\circ} \mathrm{C}, 72 \mathrm{~h}$, toluene, 20 bar $\mathrm{H}_{2}$, isolated yields and (conversions).

In conclusion, as the systematic steric tunings revealed, the modulation of back-strain is an important design element to tackle one of key constrains of B/N centered FLP hydrogenation, the water inhibition. The enhanced back-strain of LA upon complexation makes water binding increasingly reversible. In this way, we can maintain the preferential hydrogen activation ability while suppressing the interference of the water with FLP. The utility of this structurally fine-tuned FLP catalyst was demonstrated in reductive amination of carbonyls. This novel metal-free method displays a notable broad chemoselectivity and generality. As such designer catalyst may stand to enable additional advanced applications of FLP chemistry, continuing development of catalysts and application are currently underway and will be reported in due course.

\section{Acknowledgements}

The authors acknowledge financial support from National Research, Development and Innovation Office (grants K-116150 and K-115660). The authors thank László Gulyás for HRMS measurements and Tamás Pajkossy for CV measurements.

Keywords: frustrated Lewis pairs, water tolerant, strain, reductive amination, dynamic NMR

[1] Pioneering work: a) G. C. Welch, R. R. San Juan, J. D. Masuda, D. W Stephan, Science 2006, 314,1124-1126; Reviews on FLP chemistry: b) D. W. Stephan, Science 2016, 354, 1248-1256; c) D. W. Stephan, G. Erker, Angew. Chem. Int. Ed. 2015, 54, 6400-6441; d) D. W. Stephan Acc. Chem. Res. 2015, 48, 306-316; e) D. W. Stephan, J. Am. Chem. Soc. 2015, 137, 10018-10032; f) S. R. Flynn, D. F. Wass, ACS Catal. 2013, 3, 2574-2581; g) "Frustrated Lewis Pairs I-II": Topics in Current Chemistry (Eds.: G. Erker, D. W. Stephan), Springer, Heidelberg, 2013, 191-217; h) D. W. Stephan, G. Erker, Angew. Chem. Int. Ed. 2010, 49, 46-76.

[2] For reviews, see: a) D. W. Stephan, S. Greenberg, T. W. Graham, P. Chase, J. J. Hastie, S. J. Geier, J. M. Farrell, C. C. Brown, Z. M. Heiden, G. C. Welch, M. Ullrich, Inorg. Chem. 2011, 50, 12338-12348; b) D. W. Stephan, Org. Biomol. Chem. 2012, 10, 5740-5746; c) T. Soós, Pure Appl. Chem. 2011, 83, 667-675; d) J. Paradies, Synlett, 2013, 777-780; e) L. J. Hounjet, D. W. Stephan, Org. Process Res. Dev. 2014, 18, 385-391; f) L. Shi, Y.-G. Zhou, ChemCatChem 2015, 7, 54-56.

[3] For mechanism, see: a) T. A. Rokob, A. Hamza, A. Stirling, T. Soós, I. Pápai, Angew. Chem. Int. Ed. 2008, 47, 2435-2438; b) T. A. Rokob, A Hamza, I. Pápai, J. Am. Chem. Soc. 2009, 131, 10701-10710; c) S. Grimme, H. Kruse, L. Goerigk, G. Erker, Angew. Chem. Int. Ed. 2010 , 49, 1402-1405; d) T. A. Rokob, I. Bakó, A. Stirling, A. Hamza, I. Pápai, J. Am. Chem. Soc. 2013, 135, 4425-443.

[4] a) M. Lindqvist, N. Sernala, V. Sumerin, K. Chernichenko, M. Leskelä; T. Repo, Dalton Trans. 2012, 41, 4310-4312; b) L. E. Longobardi, C. Tang, D. W. Stephan, Dalton Trans. 2014, 43, 15723-15726; b) D. J. Scott, M. J. Fuchter, A. E. Ashley, J. Am. Chem. Soc. 2014, 136, 15813-15816; c) T. Mahdi, D. W. Stephan, J. Am. Chem. Soc. 2014, 136, 15809-15812; d) Á. Gyömöre, M. Bakos, T. Földes, I. Pápai, A. Domján, T. Soós, ACS Catal. 2015, 5, 5366-5372; e) D. J. Scott, T. R. Simmons, E. J. Lawrence, G. G. Wildgoose, M. J. Fuchter, A. E. Ashley, ACS Catal. 2015, 5, 5540-5544; f) M. Bakos, Á. Gyömöre, A. Domján, T. Soós, Angew. Chem. Int. Ed. 2017, DOI: 10.1002/anie.201700231.

[5] D. J. Scott, N. A. Phillips, J. S. Sapsford, A. C. Deacy, M. J. Fuchter, A. E. Ashley, Angew. Chem. Int. Ed. 2016, 55, 14738-14742.

[6] Auto-tandem condensation-reduction FLP reactions using silane reducing agents a) M.-C. Fu, R. Shang, W.-M. Cheng, Y. Fu, Angew. Chem. Int. Ed. 2015, 54, 9042-9046; b) V. Fasano, J. E. Radcliffe, M. J. Ingleson, ACS Catal. 2016, 6, 1793-1798; c) M. R. Tiddens, R. J. M. K. Gebbink, M. Otte, Org. Lett. 2016, 18, 3714-3717; d) V. Fasano, M. J. Ingleson, Chem. Eur. J. 2017, 23, 2217-2224.

[7] For reviews, see: a) J. Martens, Houben-Weyl Methods of Organic Chemistry, $4^{\text {th }}$ Ed.,; (Eds.: G. Helmchen, R. W. Hoffmann, J. Mulzer, E. Schaumann), Thieme, Stuttgart, 1995, Vol. E21d, 4199-4238; b) E. W. Baxter, A. B. Reitz, Organic Reactions, Vol. 59; Wiley: New York, 2002, 1; c) S. Gomez, J. A. Peters, T. Maschmeyer, Adv. Synth. Catal. 2002 
344, 1037-1057; d) Chiral Amine Synthesis, Ed. T. C. Nugent, Wiley$\mathrm{VCH}, 2010$. For selected catalytic examples, see: e) V. I. Tararov, R Kadyrov, T. H. Riermeier, C. Fischer, A. Börner, Adv. Synth. Catal. 2004, 346, 561-565; f) D. Menche, J. Hassfeld, J. Li, G. Menche, A. Ritter, S. Rudolph, Org. Lett. 2006, 8, 741-744; g) R. I. Storer, D. E. Carrera, Y. Ni, D. W. C. MacMillan, J. Am. Chem. Soc. 2006, 128, 84-86 h) A. Pagnoux-Ozherelyeva, N. Pannetier, M. D. Mbaye, S. Gaillard, J. L. Renaud, Angew. Chem. Int. Ed. 2012, 51, 4976-4980; i) D. Chusov, B. List, Angew. Chem. Int. Ed. 2014, 53, 5199-5201; j) S. Zhou, S. Fleischer, H. Jiao, K. Junge, M. Beller, Adv. Synth. Catal. 2014, 356 3451-3455; k) T. Huber, L. Schneider, A. Präg, S. Gerhardt, O. Einsle, M. Müller, ChemCatChem 2014, 6, 2248-2252; I) T. Stemmler, A.-E. Surkus, M.-M. Pohl, K. Junge, M. Beller, ChemSusChem 2014, 7 , 3012-3016; m) S. Pisiewicz, T. Stemmler, A.-E. Surkus, K. Junge, M. Beller, ChemCatChem 2015, 7, 62-64; m) Y. Ogiwara, T. Uchiyama, N. Sakai, Angew. Chem. Int. Ed. 2016, 55, 1864-1867; n) H. Huang, X Liu, L. Zhou, M. Chang, X. Zhang, Angew. Chem. Int. Ed. 2016, 55 5309-5312; o) P. Yang, L. H. Lim, P. Chuanprasit, H. Hirao, J. Zhou, Angew. Chem. Int. Ed. 2016, 55, 12083-12087; p) A. Pushpanath, E. Siirola, A. Bornadel, D. Woodlock, U. Schell, ACS Catal. 2017, 7 3204-3209; q) Q. Zhang, S.-S. Li , M.-M. Zhu, Y.-M. Liu, H.-Y. He, Y. Cao, Green Chem. 2016, 18, 2507-2513; r) O. I. Afanasyev, A. A Tsygankov, D. L. Usanov, D. S. Perekalin, N. V. Shvydkiy, V. I. Maleev, A. R. Kudinov, D. Chusov, ACS Catal. 2016, 6, 2043-2046; s) D. Wetzl, M. Gand, A. Ross, H. Müller, P. Matzel, S. P. Hanlon, M. Müller, B. Wirz M. Höhne, H. Iding, ChemCatChem 2016, 8, 2023-2026; t) B. Song, C.-B. Yu, Y. Ji, M.-W. Chen, Y.-G. Zhou, Chem. Commun. 2017, 53 1704-1707; Stoichiometric borane methods: u) C. F. Lane, Synthesis 1975,135-146; v) K. Gilmore, S. Vukelić, D. T. McQuade, B. Koksch, P. H. Seeberger, Org. Process Res. Dev. 2014, 18, 1771-1776;

[8] C. Bergquist, B. M. Bridgewater, C. J. Harlan, J. R. Norton, R. A. Friesner, G. Parkin, J. Am. Chem. Soc. 2000, 122, 10581-10590.
[9] a) G. Erős, H. Mehdi, I. Pápai, T. A. Rokob, P. Király, G. Tárkányi, T. Soós, Angew. Chem. Int. Ed. 2010, 49, 6559-6563; b) G. Erős, K Nagy, H. Mehdi, I. Pápai, P. Nagy, P. Király, G. Tárkányi, T. Soós, Chem. Eur. J. 2012, 18, 574-585.

[10] a) H. C. Brown, H. I. Schlesinger, S. Z. Cardon, J. Am. Chem. Soc 1942, 64, 325-329.; b) Steric Effects In Organic Chemistry (Ed. M. S. Newmann), Wiley \& Sons Inc., 1956, pp. 454. c) H. C. Brown, J. Chem Soc. 1956, 1248-1268; d) P. A. Chase, L. D. Henderson, W. E. Piers M. Parvez, W. Clegg, M. R. J. Elsegood, Organometallics 2006, 25, 349-357.

[11] A. E. Ashley, T. J. Herrington, G. G. Wildgoose, H. Zaher, A. L. Thomp son, N. H. Rees, T. Krämer, D. O'Hare, J. Am. Chem. Soc. 2011, 133 14727-14740.

[12] a) V. Gutmann, Coord. Chem. Rev. 1975, 15, 207-237; b) M. A. Beckett, Polym. Comm. 1996, 37, 4629; c) G. J. P. Britovsek, J. Ugolotti, A. J. P. White, Organometallics 2005, 24, 1685-1691.

[13] Hydricity and relative hydricity to evaluate boranes for FLP reactions: a) E. S. Wiedner, M. B. Chambers, C. L. Pitman, R. M. Bullock, A. J. M. Miller, A. M. Appel, Chem. Rev. 2016, 116, 8655-8692; b) E. R. Clark, A. Del Grosso, M. J. Ingleson, Chem. Eur. J. 2013, 19, 2462-2466; c) H. Böhrer, N. Trapp, D. Himmel, M. Schleep, I. Krossing, Dalton Trans. 2015, 44, 7489; d) É. Dorkó, B. Kótai, T. Földes, Á. Gyömöre, I. Pápai, T. Soós, J. Organomet. Chem. 2017, doi.org/10.1016/j.jorganchem.2017.04.031.

[14] Solution phase Gibbs free energies were obtained from B3LYP-D3/6$311++\mathrm{G}(3 \mathrm{df}, 3 \mathrm{pd})$ electronic energies and additional terms from B3LYP D3/6-311G(d,p) calculations. For computational details, see Supporting Information.

[15] C. L. Perrin, T. J. Dwyer, Chem. Rev. 1990, 90, 935-967. 
Entry for the Table of Contents (Please choose one layout)

\section{COMMUNICATION}

We report here the development of a boron/nitrogen centered frustrated Lewis pair with remarkable high water tolerant property. As systematic steric tuning of the boron-based Lewis acid component revealed, the enhanced back-strain engenders water binding increasingly reversible in the presence of relatively strong base. This advance allows to expand the limit of FLP's hydrogenation as demonstrated by the FLP reductive amination of carbonyls.

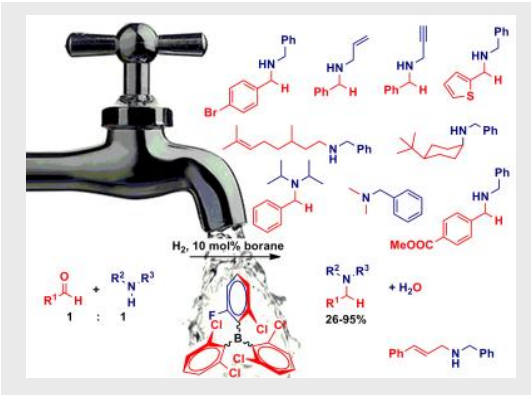

Éva Dorkó, Márk Szabó, Bianka Kótai, Imre Pápai, Attila Domján and Tibor Soós*

Page No. - Page No.

Expanding the Boundary of Water Tolerant Frustrated Lewis Pair Hydrogenation: Enhanced Back Strain in the Lewis Acid Enables the Reductive Amination of Carbonyls 